\title{
Enhanced Performance of Dye-Sensitized Solar Cells with Nanostructure Graphene Electron Transfer Layer
}

\author{
Chih-Hung Hsu, Jia-Ren Wu, Lung-Chien Chen, Po-Shun Chan, and Cheng-Chiang Chen \\ Department of Electro-Optical Engineering, National Taipei University of Technology, No. 1, Section 3, \\ Chung-Hsiao E. Road, Taipei 106, Taiwan \\ Correspondence should be addressed to Lung-Chien Chen; ocean@ntut.edu.tw
}

Received 8 November 2013; Revised 3 February 2014; Accepted 3 February 2014; Published 5 March 2014

Academic Editor: J.M.P.Q. Delgado

Copyright (C) 2014 Chih-Hung Hsu et al. This is an open access article distributed under the Creative Commons Attribution License, which permits unrestricted use, distribution, and reproduction in any medium, provided the original work is properly cited.

The utilization of nanostructure graphene thin films as electron transfer layer in dye-sensitized solar cells (DSSCs) was demonstrated. The effect of a nanostructure graphene thin film in DSSC structure was examined. The nanostructure graphene thin films provides a great electron transfer channel for the photogenerated electrons from $\mathrm{TiO}_{2}$ to indium tin oxide (ITO) glass. Obvious improvements in short-circuit current density of the DSSCs were observed by using the graphene electron transport layer modified photoelectrode. The graphene electron transport layer reduces effectively the back reaction in the interface between the ITO transparent conductive film and the electrolyte in the DSSC.

\section{Introduction}

Dye-sensitized solar cells (DSSCs), also known as Grätzel's cell, are of particular interest in the field of solar energy owing to their low cost and simplicity of fabrication [1-5]. The DSSCs have a basic structure that comprises two conductive substrates, an absorbing layer of semiconductor materials with wide band gap, dye molecules, and a redox electrolyte.

The basic principle of operation of DSSCs is that electrons are injected from the photoexcited dye into the conductive band of the semiconductor under illumination; meanwhile, the electrolyte reduces the oxidized dye and transports the positive charges to the counter electrode. However, one of the major issues hindering the rapid commercialization of DSSCs is their lower conversion efficiency compared to conventional p-n junction solar cells [6]. That may be attributed to poor charge separation in DSSC structure. Therefore, charge transfer structure, such as Au nanoparticles and quantum dots, has been employed in a DSSC to improve the device performance through charge separation in the photoelectrodes [7-10]. Graphene is a potential material for many applications due to their high electron mobility, outstanding optical properties, and thermal, chemical, and mechanical stability [11-15]. Therefore, this study investigates the effect on the graphene layer as electron transport layer in the DSSC structure deposited by the magnetron sputtering method; in particular, it examines the performance of the DSSCs with the graphene electron transport layer.

\section{Experimental}

A $60 \mathrm{~nm}$ thick graphene layer was sputtered on indium tin oxide (ITO) conductive glass substrate by radio-frequency magnetron sputtering using a graphite target as an electron transport layer to improve the electron transfer in the DSSC structure. Next, the solution consisting of $1 \mathrm{~g} \mathrm{\textrm {TiO } _ { 2 }}$ nanocrystalline powder with diameter $\sim 25 \mathrm{~nm}, 1 \mathrm{~mL}$ of triton X-100, acetic acid, and deionized water were mixture as colloidal solution, and the colloidal solutions were daubed uniformly onto the graphene electron transfer layer to form a thick film. The films were annealed at $450^{\circ} \mathrm{C}$ for $10 \mathrm{~min}$. Thereafter, the photoelectrode with the graphene layer was immersed in a $3 \times 10^{-4} \mathrm{M}$ solution of N719 dye adsorption $\left(\left(\mathrm{Bu}_{4} \mathrm{~N}\right)_{2}\right.$ $\left[\mathrm{Ru}(\mathrm{dcbpyH})_{2}(\mathrm{NCS})_{2}\right]$ complex $)$ in ethanol for $24 \mathrm{hr}$, before being sintered at $450^{\circ} \mathrm{C}$ for $30 \mathrm{~min}$, to increase its anatase content. The electrolyte was composed of $0.05 \mathrm{M}$ iodide and $0.5 \mathrm{M}$ lithium iodide with and without $0.5 \mathrm{M}$ 4-tertbutylpyridine (TBP) in propylene carbonate. Then, a $100 \mathrm{~nm}$ thick layer of platinum was sputtered onto ITO substrate as a counter electrode. Cells were fabricated by placing sealing 


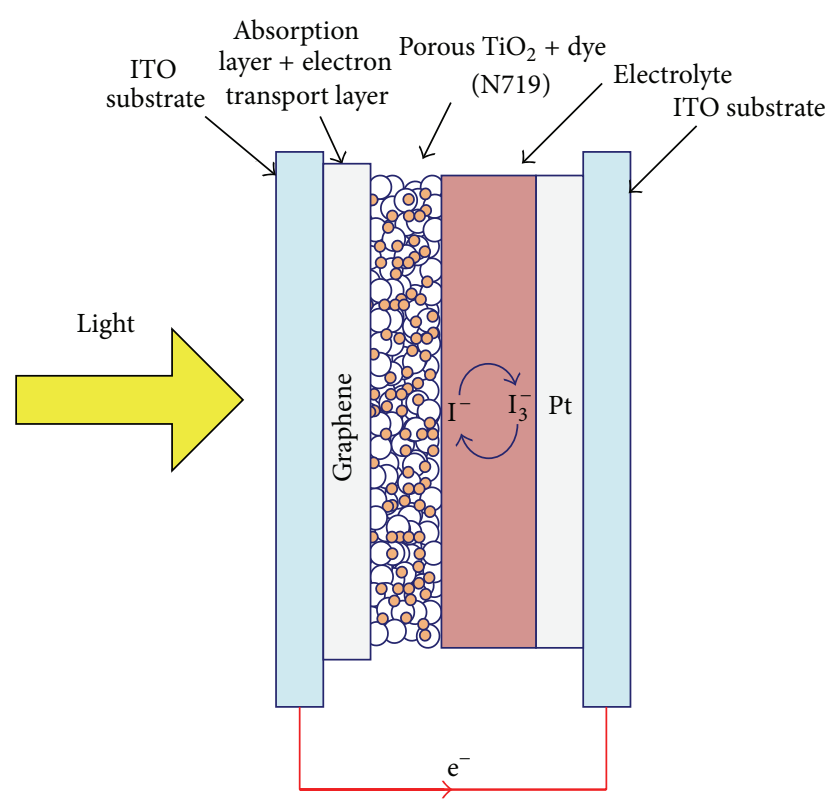

FIGURE 1: Schematic cross-section of the completed structure.

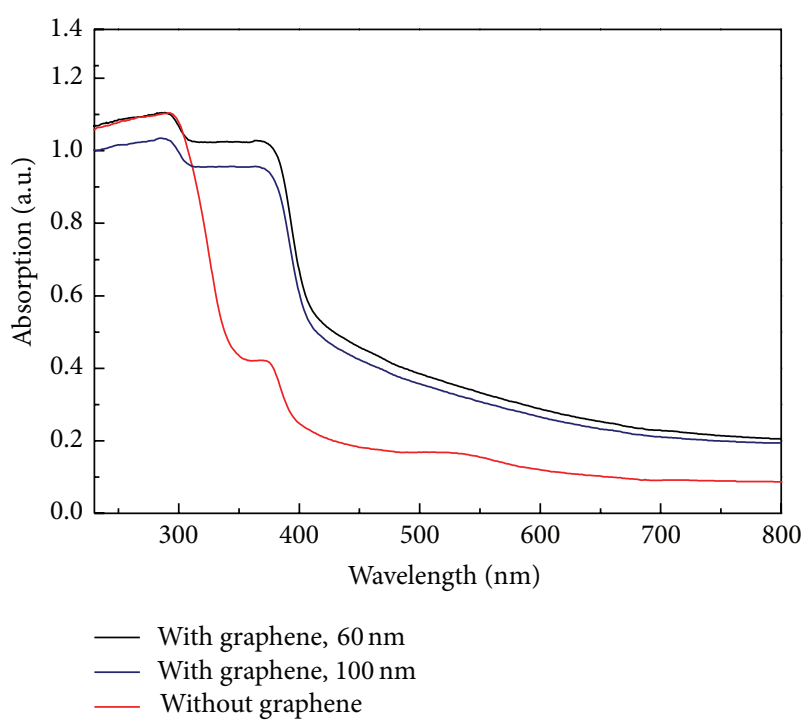

FIGURE 2: Absorbance spectra of the DSSCs with and without the graphene electron transfer layer.

films (SX1170-60, SOLARONIX) between the two electrodes and leaving just two via-holes for injection electrolyte. The sealing process was carried out on a hot plate at $100^{\circ} \mathrm{C}$ for $3 \mathrm{~min}$. Then, the electrolyte was injected into the space between the two electrodes through the via-holes. Finally, the via-holes were sealed using the epoxy with low vapor transmission rate. Figure 1 schematically depicts the complete structure. Figure 1 shows the cross-section of the completed structure. The current density-voltage $(J-V)$ characteristics were measured using a Keithley 2420 programmable source meter under irradiation by a $1000 \mathrm{~W}$ xenon lamp. Finally, the irradiation power density on the surface of the sample was calibrated at $100 \mathrm{~mW} / \mathrm{cm}^{2}$.

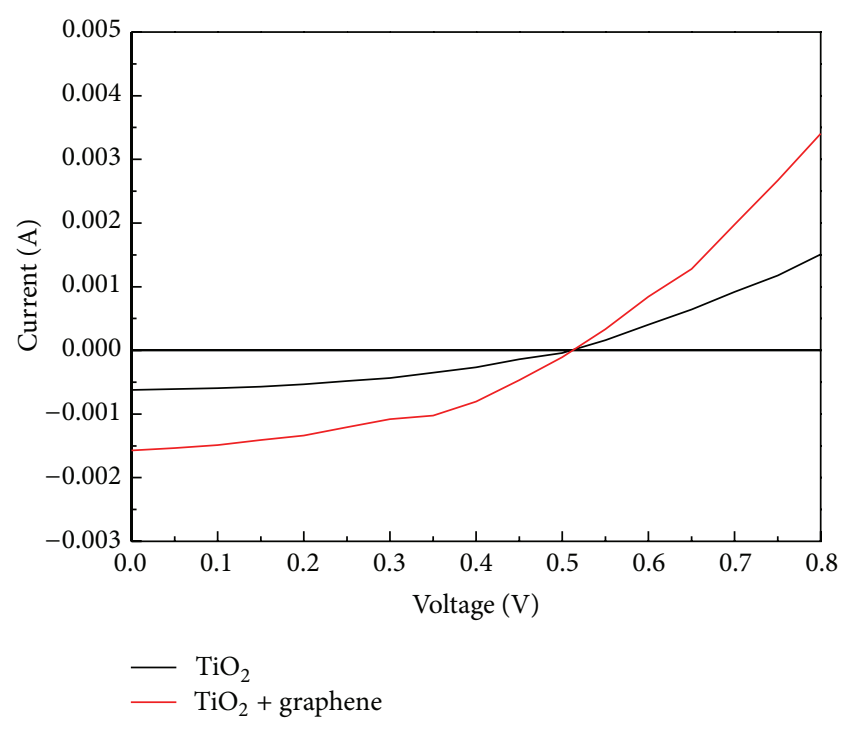

Figure 3: $J-V$ curves of the DSSCs with and without the graphene electron transfer layer under illumination.

\section{Results and Discussion}

Figure 2 shows the absorption of $\mathrm{TiO}_{2}$ DSSCs with and without the graphene electron transfer layer. Absorption of the DSSC with the $60 \mathrm{~nm}$ thick graphene electron transport layer has obviously higher absorption intensity than the DSSC with the $100 \mathrm{~nm}$ thick graphene electron transport layer and without the graphene electron transport layer in visible range, especially in the range of $310-400 \mathrm{~nm}$. That means the graphene electron transport layer has an increased absorption coefficient. Therefore, the graphene electron transport layer is also as an absorption layer to improve the absorption of the solar cells.

Figure 3 shows the $I-V$ characteristics of the DSSCs. The cell performance was measured under AM 1.5 illumination with a solar intensity of $100 \mathrm{~mW} / \mathrm{cm}^{2}$ at $25^{\circ} \mathrm{C}$. The cell has an active area of $3 \times 3 \mathrm{~mm}^{2}$ and no antireflective coating. The measured cell parameters, open-circuit voltage $\left(V_{\mathrm{oc}}\right)$, shortcircuit current $\left(J_{\mathrm{sc}}\right)$, fill factor $(\mathrm{FF})$, and energy conversion efficiency $\left(E_{\mathrm{ff}}\right)$ are shown in Table 1. As shown in Figure 3, $\mathrm{TiO}_{2}$ DSSCs with graphene electron transfer layer exhibited the following static parameters: $V_{\mathrm{oc}}$ of $0.5 \mathrm{~V}$ and $J_{\mathrm{sc}}$ of $17.5 \mathrm{~mA} / \mathrm{cm}^{2}$. The fill factor (FF) can be estimated by [16]

$$
\mathrm{FF}=\frac{J_{m} V_{m}}{J_{\mathrm{sc}} V_{\mathrm{oc}}},
$$

where $J_{m}$ is the maximum output current density and $V_{m}$ is the maximum output voltage. Therefore, the value of FF results is equal to 0.456 . Similarly, the energy conversion efficiency $\left(E_{\mathrm{ff}}\right)$ can be calculated by [16]

$$
E_{\mathrm{ff}}=\frac{J_{m} V_{m}}{P_{\text {inc }}}
$$

with $P_{\text {inc }}$ as the incident power and $E_{\mathrm{ff}}$ results to be $3.98 \%$, respectively. The improvement may be attributed to 


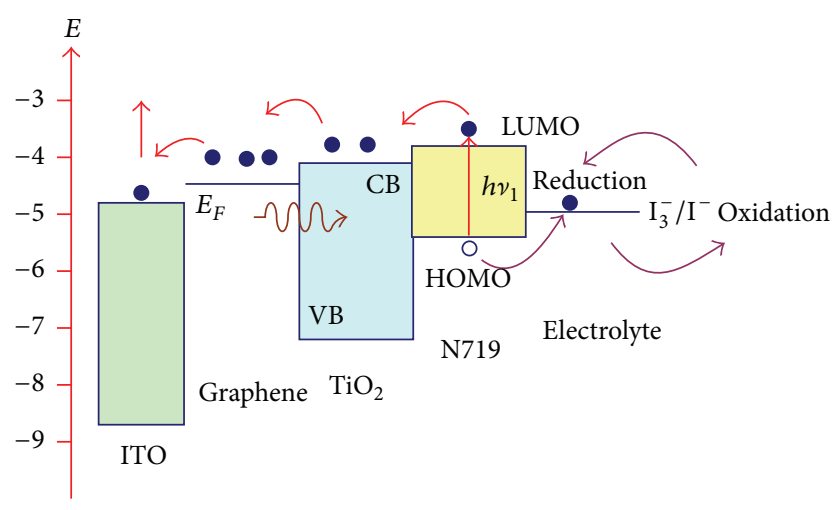

Figure 4: Energy level diagram and mechanism of photocurrent generation in the DSSCs with the graphene electron transfer layer.

TABLE 1: The parameters for $\mathrm{TiO}_{2}$ DSSCs with and without graphene electron transport layer.

\begin{tabular}{lcc}
\hline & $\mathrm{TiO}_{2}$ & Graphene $+\mathrm{TiO}_{2}$ \\
\hline$J_{\text {sc }}\left(\mathrm{mA} / \mathrm{cm}^{2}\right)$ & 6.9 & 17.5 \\
$V_{\text {oc }}(\mathrm{V})$ & 0.5 & 0.5 \\
$\mathrm{FF}$ & 0.419 & 0.456 \\
$\eta(\%)$ & 1.45 & 3.98 \\
\hline
\end{tabular}

the incorporation of the graphene electron transport layer. Figure 4 shows the energy level diagram and mechanism of photocurrent generation in $\mathrm{TiO}_{2}$ DSSCs with the graphene layer. The work function of the graphene layer is around $4.5 \mathrm{eV}[17,18]$. Graphene has a work function similar to that of the ITO $(4.8 \mathrm{eV})$ electrode. The graphene layer does not prevent the flow of injected electrons down to the ITO electrode because its work function exceeds that of the ITO electrode [19-21]. The CB and VB are the conduction band and valence band, respectively. The LUMO and HOMO are the lowest unoccupied molecular orbit and highest occupied molecular orbit, respectively. Therefore, the brief operating process is as follows. Dye N719 was excited by incident light, and electrons transit from HOMO to LUMO. Electrons are injected into the graphene electron transport layer via the $\mathrm{TiO}_{2}$ photoelectrode. The electrons transferred to the graphene electron transport layer were collected at the back contact to generate a photocurrent. Therefore, the inserted graphene layer collects electrons and acts as a transporter in the effective separation of charge and rapid transport of the photogenerated electrons. According to Figures 2 and 3, the enhanced performance of DSSCs with a graphene was attributed to the increase in electron transport efficiency and light absorption in visible range.

\section{Conclusions}

DSSCs with a graphene electron transport layer were prepared on an indium tin oxide glass substrate by radiofrequency magnetron sputtering. This work discusses the improvement associated with the introduction of a graphene layer in DSSCs. The enhanced performance of DSSCs with a graphene may be attributed to the increase in electron transport efficiency and light absorption in visible range, especially in the range of $310-400 \mathrm{~nm}$. Therefore, the shortcircuit current density and efficiency of conversion of solar energy to electricity were increased from $6.9 \mathrm{~mA} / \mathrm{cm}^{2}$ and $1.45 \%$ to $17.5 \mathrm{~mA} / \mathrm{cm}^{2}$ and $3.98 \%$, respectively, under simulated full sun illumination. By incorporation of the graphene electron transport layer, the device efficiency can be increased by over $170 \%$.

\section{Conflict of Interests}

The authors declare that there is no conflict of interests regarding the publication of this paper.

\section{Acknowledgment}

The financial support of this paper was provided by the National Science Council of the Republic of China under Contract no. NSC 102-2622-E-027-021-CC3.

\section{References}

[1] B. O'Regan and M. Gratzel, "A low-cost, high-efficiency solar cell based on dye-sensitized colloidal $\mathrm{TiO}_{2}$ films," Nature, vol. 353, no. 6346, pp. 737-740, 1991.

[2] B. O’Regan, J. Moser, M. A. Anderson, and M. Gratzel, "Vectorial electron injection into transparent semiconductor membranes and electric field effects on the dynamics of lightinduced charge separation," The Journal of Physical Chemistry, vol. 94, no. 24, pp. 8720-8726, 1990.

[3] N. G. Park, J. van de Lagemaat, and A. J. Frank, "Comparison of dye-sensitized rutile- and anatase-based $\mathrm{TiO}_{2}$ solar cells," The Journal of Physical Chemistry B, vol. 104, no. 38, pp. 8989-8994, 2000.

[4] M. Y. Song, D. K. Kim, K. J. Ihn, S. M. Jo, and D. Y. Kim, "Electrospun $\mathrm{TiO}_{2}$ electrodes for dye-sensitized solar cells," Nanotechnology, vol. 15, no. 12, pp. 1861-1865, 2004.

[5] J. Bisquert, D. Cahen, G. Hodes, S. Rühle, and A. Zaban, "Physical chemical principles of photovoltaic conversion with nanoparticulate, mesoporous dye-sensitized solar cells," The Journal of Physical Chemistry B, vol. 108, no. 24, pp. 8106-8118, 2004.

[6] T. Bora, H. H. Kyaw, S. Sarkar, S. K. Pal, and J. Dutta, "Highly efficient $\mathrm{ZnO} / \mathrm{Au}$ Schottky barrier dye-sensitized solar cells: role of gold nanoparticles on the charge-transfer process," Beilstein Journal of Nanotechnology, vol. 2, no. 1, pp. 681-690, 2011.

[7] C. Hagglund, M. Zach, and B. Kasemo, "Enhanced charge carrier generation in dye sensitized solar cells by nanoparticle plasmons," Applied Physics Letters, vol. 92, no. 1, Article ID 013113, 2008.

[8] S. Barazzouk and S. Hotchandani, "Enhanced charge separation in chlorophyll a solar cell by gold nanoparticles," The Journal of Applied Physics, vol. 96, no. 12, pp. 7744-7746, 2004.

[9] S. W. Tong, C. F. Zhang, C. Y. Jiang et al., "Improvement in the hole collection of polymer solar cells by utilizing gold nanoparticle buffer layer," Chemical Physics Letters, vol. 453, no. 1-3, pp. 73-76, 2008. 
[10] L. C. Chen, C. C. Wang, and B. S. Tseng, "Enhancement in nanocrystalline $\mathrm{TiO}_{2}$ solar cells sensitized with $\mathrm{ZnPc}$ by nanoparticles," Journal of Optoelectronic and Biomedical Materials, vol. 1, no. 3, pp. 249-254, 2009.

[11] X. Du, I. Skachko, A. Barker, and E. Y. Andrei, "Approaching ballistic transport in suspended grapheme," Nature Nanotechnology, vol. 3, no. 8, pp. 491-495, 2008.

[12] R. R. Nair, P. Blake, A. N. Grigorenko et al., "Fine structure constant defines visual transparency of graphene," Science, vol. 320, no. 5881, p. 1308, 2008.

[13] X. Wang, L. Zhi, N. Tsao, Z. Tomovic, J. Li, and K. M. Müllen, "Transparent carbon films as electrodes in organic solar cells," Angewandte Chemie International Edition, vol. 47, no. 16, pp. 2990-2992, 2008.

[14] X. Wang, L. Zhi, and K. Müllen, "Transparent, conductive graphene electrodes for dye-sensitized solar cells," Nano Letters, vol. 8, no. 1, pp. 323-327, 2008.

[15] S. Bae, H. Kim, Y. Lee et al., "Roll-to-roll production of 30-inch graphene films for transparent electrodes," Nature Nanotechnology, vol. 5, no. 8, pp. 574-578, 2010.

[16] S. M. Sze, Physics of Semiconductor Devices, John Wiley \& Sons, New York, NY, USA, 2nd edition, 1981.

[17] M. Koshino and T. Ando, "Electronic structures and optical absorption of multilayer graphenes," Solid State Communications, vol. 149, no. 27-28, pp. 1123-1127, 2009.

[18] G. Giovannetti, P. A. Khomyakov, G. Brocks, V. M. Karpan, J. van den Brink, and P. J. Kelly, "Doping graphene with metal contacts," Physical Review Letters, vol. 101, no. 2, Article ID 026803, 2008.

[19] R. Czerw, B. Foley, D. Tekleab, A. Rubio, P. M. Ajayan, and D. L. Carroll, "Substrate-interface interactions between carbon nanotubes and the supporting substrate," Physical Review B, vol. 66, Article ID 033408, 2002.

[20] A. Kongkanand, R. Martinez-Dominguez, and P. V. Kamat, "Single wall carbon nanotube scaffolds for photoelectrochemical solar cells. Capture and transport of photogenerated electrons," Nano Letters, vol. 7, no. 3, pp. 676-680, 2007.

[21] F. Xu, J. Chen, X. Wu et al., "Graphene scaffolds enhanced photogenerated electron transport in $\mathrm{ZnO}$ photoanodes for highefficiency dye-sensitized solar cells," The Journal of Physical Chemistry C, vol. 117, pp. 8619-8627, 2013. 

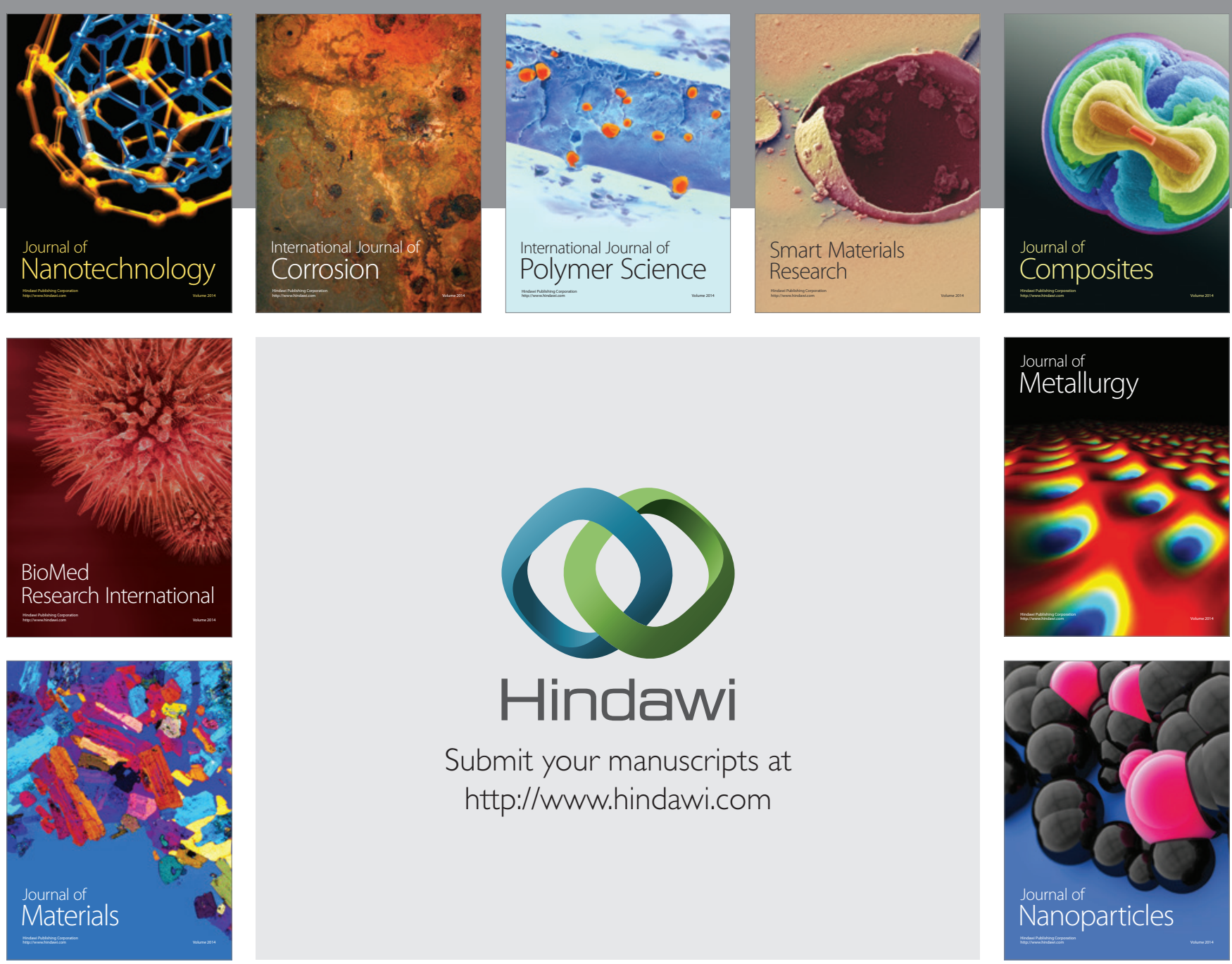

Submit your manuscripts at http://www.hindawi.com
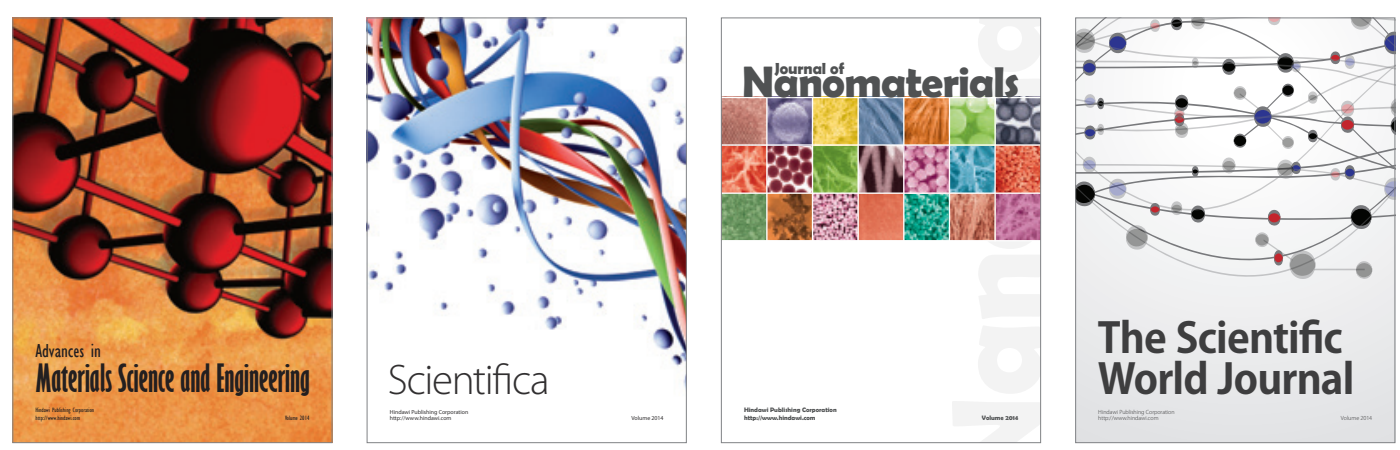

\section{The Scientific World Journal}
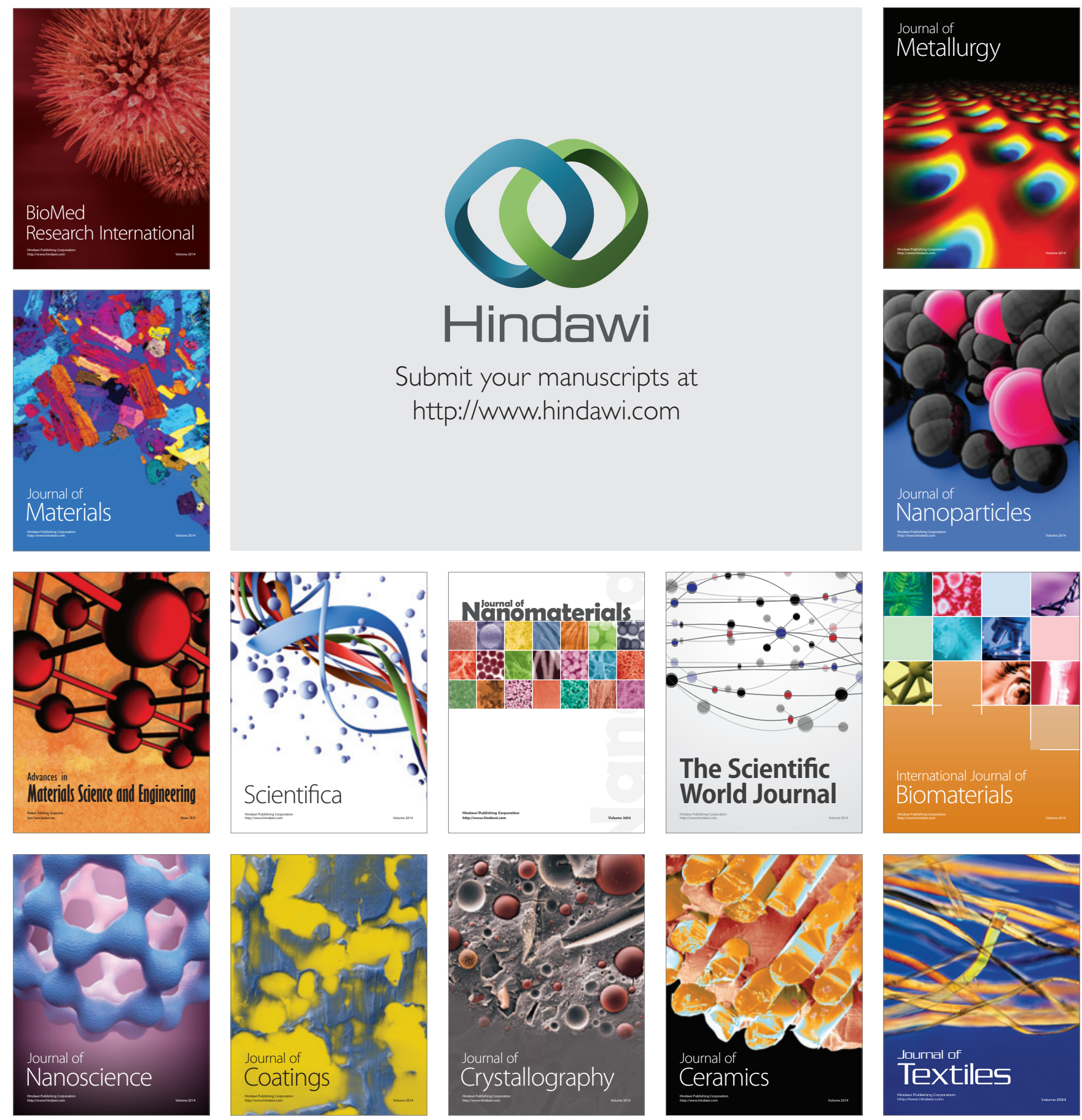